\title{
The Village Antique Mall: A Case Study
}

John Cooley, West Texas A\&M University, USA

James Owens, West Texas A\&M University, USA

Neil Terry, West Texas A\&M University, USA

\begin{abstract}
This case applies economic competition fundamentals to the situation of competing in the market for antiques and growing a business for the purpose of cap selling a building. The macro perspective of the case describes technology and demographic changes that have modified the nature of competition for antiques. The micro perspective of the case describes how The Village Antique Mall in Amarillo, Texas matured as a business in light of the changes to competitive forces. Price, location, attribute differences, firm-service differentials, and differentiated subjective image in the form of advertising are the primary forms of competition explored in the case.
\end{abstract}

Keywords: Antiques; Business Information Systems; Competition; Marketing; Microeconomic Theory

\section{INTRODUCTION}

\begin{abstract}
im and Lynn Stanley walked into their vacant Amarillo, Texas building which is over 32,000 square feet over four floors and previously housed a furniture store that had been shut down two years prior. As they walked through the different floors, the amount of empty space looked formidable. It was time to either sell it, lease it or start a new business, since minimal utilities and upkeep was expensive.
\end{abstract}

\section{THE DECISION}

Jim had talked with a commercial realtor from Dallas a few weeks prior concerning the sale of the building but felt that the prices discussed were below the desired value by a substantial amount. During the discussion, the Dallas realtor raised the concept of "cap" selling the facility. "Cap" valuation is relatively common in valuing small business wherein a multiplier or "capitalization factor" is taken times net earnings to estimate the market value of the ongoing enterprise. It is a simplified version of a traditional discounted cash flow (DCF) analysis, which is often used in the negotiation phase of a potential sale. Selling the space with an ongoing and viable business in place would result in a better price than selling it as empty real estate. Jim talked to Lynn about the concept and, while both agreed it was attractive, they would have to find and put an operating business in place since neither was particularly interested in starting up a new enterprise from scratch. An ideal solution would be to purchase an existing business and expand sufficiently over a period of three to five years in order to effectively utilize the entire 32,000 square feet. The business could produce an income for Jim and Lynn while providing cash flow for maintenance and physical updates. They were also cognizant that they did not personally have either time or desire to manage the new business on a full-time basis so would need to employ someone to handle the daily operations.

\section{THE SCENERIO DEVELOPS}

A few months later, Jim received a call from a woman inquiring about the possibility of renting some space. The person making the inquiry owned a small business called The Village Antique Mall. A cursory discussion revealed that she was currently leasing about 7,000 square feet of space, which would be one floor of the empty building. Jim explained that he would need to lease more than one floor of the building. The owner of the Mall believed that the business could grow over time to encompass the other floors. Jim thanked her for her time and said he would think about leasing the building; however, it did not seem plausible at that point. 
Over the next few weeks, Lynn and Jim talked further and felt that The Village Antique Mall could be a business they could grow to fill the extra space. They decided it would be better if Jim and Lynn would buy the business and let the current owner be the general manager of daily operations. Within a couple of weeks, Jim and Lynn presented the idea of purchasing the business, including business software and the business name, for a nominal amount but make the current owner the general manager of operations. Her compensation as general manager included a salaried position and $1 \%$ of net sales as a bonus. In addition, she would have to convince the current mall vendors who rented space to move to the new facility. After additional discussion, an agreement to purchase the business and move operations was reached.

On April 7, 2007, The Village Antique Mall opened at the new location and approximately $98 \%$ of the original vendors moved to the new building. In addition to renting space on a square foot basis, the Mall retained $10 \%$ of gross sales from the vendors. The idea now was to grow the business as quickly as possible.

\section{THE ECONOMIC AND TECHNOLOGICAL LANDSCAPE}

The economic difficulties, beginning with the September 2008 financial crisis, are familiar to most participants in the broad United States economy. Unemployment was consistently in the mid-four percent range throughout 2007 and soared to a high of 10 percent by October 2009. It remained in the nine percent range from most of 2009 through the bulk of 2011. Disposable personal income per capita declined dramatically, in relative terms, from mid-2008 to mid-2010. The reality of a difficult five-year economic period was irrefutable and it impacted a number of industry groups with strong links to consumer spending. When inflation adjusted disposable income per capita remained effectively flat from 2007 through 2012, it was easy to see why consumer spending on particular items suffered dramatically.

Not too many years ago, most people shopped in their local stores complete with parking and weather problems, long lines, and wobbly shopping carts. Even when online shopping was available, people felt uncomfortable using their credit cards and giving their personal information to cyber-shops. That has all changed. Throughout the world, online buying has grown exponentially. Consumers may still be concerned about the security of online shopping, but more and more of them are prepared to buy on the web. Faster delivery, easier return policies, and many sites offering free shipping have increased the desirability of online buying. IBIS World research forecasts an $8.6 \%$ per year increase in online revenues over the next five years (IBS, 2013). The engine for the growth in online shopping is strong consumer demand combined with an increasing number of available products. In addition, physical stores are moving at least part of their companies online in order to cut costs.

The increase in online buying is a positive sign in an otherwise stagnant economic environment. A 2012 IBS World survey of U.S. online customers found that $82 \%$ are satisfied with buying experiences that began and ended with online merchants. Satisfaction dropped to $61 \%$ when they researched online and then bought in a store. On average, retailers that have both a physical (store) and online presence have reported an average of $23 \%$ growth (IBS, 2013). In contrast, online-only retailers (including catalogue sales) have grown at a more modest rate of $9 \%$ per year. Shoppers are beginning to think that the best deals are available online (71\%) and that they have access to lower prices online $(66 \%)$. The internet is only going to become more popular as time goes by and purchasers worldwide have become more comfortable about the security and on-time delivery of their purchases. Brick and mortar operations, like The Village Antique Mall, face the challenge of adapting their operation to the global reality of e-commerce competition.

\section{ANTIQUES IN THE MODERN BUSINESS ENVIRONMENT}

Antique stores and malls (i.e., a collection of individual dealer booths in a relatively larger store) have been subjected to an almost perfect storm given the trends noted in the previous section combined with some other economic developments. For example, as the baby boomers reached the peak of their consumption years and began to address the issues of downsizing, many of them were no longer accumulating the quantity nor the quality levels of antique furniture that was acquired in the 1970's and 1980's when they were furnishing a larger home for a family with vintage furniture that was often considered to be of higher quality than the current mass-produced furniture or that invoked memories of items seen or used during their childhood. Large homes often could comfortably 
accommodate the armoires and china cabinets commonly found in higher-end European homes and being imported to the United States for resale in antique stores. It was not unusual for an antique store catering to this clientele to make annual trips to Europe in order to acquire container loads of furniture for export to the United States. Much of the furniture was relatively heavy in design and construction.

As tastes changed and younger consumers leaned more toward furnishings with much lighter color and feel, the demand for this heavier furniture declined simultaneously with increasing amounts of it becoming available as the baby boomers were attempting to sell some of their items as part of the downsizing process. Together with the advent of services such as E-Bay and CraigsList, a dramatic increase in supply of these items was created with the inevitable result that prices sharply declined and many of the dealers, in both their own retail locations and in antique mall booths, found it increasingly difficult to sell their items at the desired prices. Granted, many consumers still prefer the idea of touch \& feel when shopping for items such as furniture, but the advent of multiple pictures in an auction offering an automatic mechanism to use the mouse for close-up views reduces the benefits of touch \& feel. Current E-Bay sellers can list up to $\$ 5,000$ worth of items per month at no listing fee, which includes multiple pictures being uploaded. They also provide automatic relisting of items that do not sell, along with extensive training materials on how to make items more marketable.

In 2012, $\$ 75$ billion worth of items were sold on E-Bay alone with a smaller, but still significant, amount being sold on CraigsList and similar local classified ad sites. It is no secret that antiques sell well on eBay and other online marketplaces. Buying antiques online allows customers to go beyond their local antique store and increase the probability of finding the items they want.

Collecting as a hobby can be a fun, worthwhile, and potentially lucrative way to pass time. Amassing collectibles as investments, however, can be a disappointing endeavor, yielding nothing but piles of devalued items for the next of kin to sort through. The changes in taste, the changes in attitude toward collecting items of interest, such as lunch boxes, figurines, company metal signs and the like, has similarly seen a downward trend with a negative effect on both shop owners and booth dealers (Notte, 2011). For example, Hummel figurines: This ceramic cherub first appeared in 1935 as a physical manifestation of drawings by German nun Maria Innocentia Hummel. When U.S. soldiers returned from Germany after World War II, they brought these keepsakes home for their wives and children. Goebel, the German company that created them, ratcheted up production and began selling them at dime stores, such as Woolworths, for $\$ 4$ to $\$ 5$ each. That low purchase price led to a huge secondary market, highpriced Hummel figurines and manufacturers who wanted a piece of the action. In the '60s and '70s, the figurines made their way into Hallmark stores and airport gift shops and prices skyrocketed, with the Umbrella Boy figurine retailing for as much as $\$ 1,500$. As more were produced and countless special editions cranked out, the resale value sank like a ceramic anchor. People were buying them looking at what they sell for at retail, but they could be worth $50 \%$ to $70 \%$ less on the secondary market. The bubble burst on Hummels in recent years as the generations that collected them passed away and left behind thousands of their diminishing-value dust collectors, which created an excess supply problem. Goebel shut down in 2008, but Manufaktur Rodental GmbH bought the brand in 2012 and began producing in limited supply. Though a Hummel sold for more than $\$ 1,100$ on eBay in 2013, most go for $\$ 50$ or less with prices continuing to plummet as estate sales add to the stockpile.

There are three kinds of high-profile items that antique dealers and consignment shops simply refuse to accept - Norman Rockwell plates, Precious Moments figurines, and Beanie Babies (Notte, 2011). While the last two items have become synonymous with American kitsch, the latter symbolizes the perils of using collectibles as commodities. The difference between old comic books and Beanie Babies is that people were buying Beanie Babies for a retail price of $\$ 4$ to $\$ 6$ and were hoping to sell them on eBay for $\$ 40$ to $\$ 50$. Some people bought thousands of dollars worth of Beanie Babies that ended up not being worth the retail price. While there are certain exceptions (e.g., misprinted versions of Iggy and Rainbow that sold for a combined $\$ 5,000$ and a Coral Casino bear that sold for $\$ 2,800)$, most Beanie Babies only enrich Ty Warner. The overwhelming majority of Beanie Babies end up in large lots that sell for $\$ 2$ or less per plush beanbag. That is a price on par with the resale value of collectible plates containing Norman Rockwell illustrations but still more than the return on the pastel, pink-and-purple Precious Moments figurines. Again, these types of collectibles appealed to a particular generation of collectors who are no longer collecting either due to age or income. They are not being replaced by new collectors of the same items and the items are cluttering up antique mall dealer booths with an associated decline in revenue that leads to it being an 
unprofitable hobby. The loss of dealers renting their booths leads to the mall operators being unable to justify the payment of their overhead costs and the opportunity costs associated with the building, which, in turn, results in the closure of many of the long-standing antique malls across the United States.

The inevitable result of aging baby boomers downsizing; the reduction in disposable income, particularly for the younger generations; and the explosive growth in online retailing and auctions, such as E-Bay, constitute the perfect storm that resulted in the closing of many antique stores and malls. There are more items than ever for sale at dramatically lower prices due to the excess supply created by both downsizing and online auctions, which makes it increasingly difficult for an antique dealer to earn a reasonable profit on most items. In fact, many of the dealers who bought inventory in the early 1970's with an eye toward their purchase being an investment have instead found that the values of their items have declined below the purchase price. The change in the landscape of the antique business environment requires the modern dealer to consider the fundamentals of competition as part of the strategic planning process.

\section{THEORETICAL FOUNDATION}

Companies can compete in several possible ways. For The Village Antique Mall, the primary competition issues are price, location, attribute differences, firm-service differentials, and differentiated subjective image in the form of advertising. This section puts forth a brief theoretical foundation for all five forms of competition and a brief application to the case.

Price is a traditional outlet for competition. The number of companies in a market often influences the nature of price competition. Limited competition derived from two to four firms could yield aggressive price competition in the short-run but often results in a mutual interdependence of limited price competition in the longrun. Transparency and asymmetric information are keys to pricing in the antique business. An experienced dealer has information on price and value that can often be substantially different from the explicit and intrinsic value of an item for a novice or random collector. Markup can reach as much as four times the purchase value if a dealer can buy from a motivated seller and move the product to a buyer with strong demand. The evolution of the internet and propensity for e-commerce transactions has created a more transparent market for both buyers and sellers, which often comes at the expense of the antique dealer as a facilitator.

Location can be an important aspect of competition. Sales can be highly influenced by traffic flows during business hours and consumers often value convenience shopping, especially for specialty items. The location of The Village Antique Mall is a high traffic area in a prosperous neighborhood. In addition, the mall concept for antiques provides customers with a wide variety of selection via the 32,000 square foot building. While no building can compete with robust options available in the online shopping format, a large antique mall provides customers significant shopping options in an environment that allows the opportunity to touch \& feel the items. The addition of an online presence for The Village Antique Mall creates an option for the physical and online environments to serve as complements.

Products often have unique attribute differences that influence consumer preferences. The attribute differences could be very clear, like a silk suit versus a cotton-polyester blend suit. Even minor attribute differences could yield a strong consumer preference for various individuals, as illustrated by loyal patrons of Pepsi-Cola versus Coca-Cola. Antiques are items that attract collectors or people searching for unique items. An antique mall will tend to carry a wide variety of items, which vary from nominally priced trinkets and handmade crafts to high-end furniture and jewelry that sell for several thousand dollars. The variety of items available is one of the aspects that drive business in an antique mall. The higher-end products tend to be required in order to attract the clientele that vendors seek. At the same time, moderately priced handmade crafts that find a customer base can create sales volume and cash flow that may not always be possible with the intermittent sale higher-end products.

Firm-service differentials can greatly influence the consumer shopping experience. Some companies might focus on friendly service that is customer-oriented and builds relationships. A second approach to service is a focus on expeditious service or customer convenience. Ambience is an important part of the antique shopping experience. Lighting, music, customer-service, and vendor expertise are among the traits that influence the antique shopping experience for customers that cannot be replicated in an online shopping environment. 
Advertising is a competitive outlet that allows a firm to announce product existence, price, location, and/or quality. Unlike price cuts, the initiator of an advertising campaign may enjoy market share and profit gains with retaliation taking weeks or months. Advertising can be an outlet for aggressive instincts in markets that are not suited for price competition. In general, an antique mall needs to advertise about existence in a way that will attract both customers and vendors as a dual source of revenue given vendors pay rent for space and the mall earns a percent of total sales from customer purchases. Road signage/billboards, magazine and newspaper print ads, radio and television promotions, and vendor incentives, such as reduced rent for the first month or reduced rent for productive referrals, are among the advertising efforts often employed by an antique mall.

\section{CASE QUESTIONS FOR CLASS DISCUSSION}

What competitive actions should The Village Antique Mall take in order to grow the business and fill the 32,000 square foot building? There are no explicit answers to The Village Antique Mall case, but there are several points worthy of discussion in a microeconomic theory course. Before reading the epilogue to find out how the case was resolved, answer and discuss the following questions relating to the case:

1. What are the advantages and disadvantages of creating a large physical presence for antiques in the modern economy? Are there creative ways The Village Antique Mall could create price competition with the online environment without explicitly lowering price?

2. What location advantages exist for The Village Antique Mall? Is there anything The Village Antique Mall can do to improve or accentuate location as a competitive advantage?

3. How can an operation like The Village Antique Mall approach attribute differences to create a competitive advantage?

4. Is it possible for The Village Antique Mall to create and sustain firm-service differentials in competition with other physical antique locations? Is it possible for The Village Antique Mall to create and sustain firm-service differentials in competition with online outlets?

5. How should The Village Antique Mall create a differentiated subjective image in the form of advertising? Are there any moderate expense advertising opportunities that The Village Antique Mall should pursue? Are there any substantive advertising opportunities that The Village Antique Mall should pursue?

\section{EPILOGUE}

The antique market in the city was mature and saturated at the time Jim and Lynn initiated The Village Antique Mall. Most of the antique stores were located along historic Route 66 as part of the visitor attraction of the city. The location of The Village Antique Mall was situated in the upscale part of the city and was an important point of differentiation. The image was to be one of a friendly, quiet atmosphere with true antiques, as well as vintage pieces and collectables. Some of the vendors that decided to locate in The Village Antique Mall bartered their time to work with customers to offset the cost of some of their rent. This gave immediate expertise for customers since some of the vendors were very knowledgeable in their field. In addition, tan aprons were purchased for the workers to wear with The Village Antique Mall logo, which presented a positive image to help them feel part of a team.

With this in mind, Lynn began to develop marketing strategies portraying this image. Lynn had experience working in advertising and she had an American Society of Interior Designers (ASID) certification. Jim, with a background in accounting, began to formalize the information and accounting system through QuickBooks. This system was to provide weekly and monthly reports with additional information as needed. A sizable advertising budget and accounting paper trails for the information system were implemented quickly. The Village Antique Mall also employed a firm to facilitate advertising efforts, which primarily found success via signage and print advertisements.

Moving into the Fall of 2007, The Village Antique Mall began to grow in customers and vendors. Advertising incorporating the upscale image, along with promotions and open houses for Halloween, Thanksgiving, and Christmas, began to validate the Mall's place in the market. By the end of 2007 and moving into 2008, the rental spaces on the first two floors were full and expanding into the third floor. As the building continued to fill, 
Jim and Lynn decided that a trip they had been planned for visiting England and Ireland could be used to incorporate the purchase of additional antiques. The Village Antique Mall would incorporate true antiques from Europe to supplement the merchandise supplied by partner vendors.

The trip was completed in the summer of 2008 and the Mall continued to grow with substantial rentals on the third floor and spillover beginning onto the fourth floor. Jim and Lynn's idea was to purchase enough antiques to fill most of the fourth floor and fill the entire building with items. The probability was that they would be buying most of their items from England or Ireland. Through contacts, Jim found a supplier that he and Lynn felt could supply the type of product that would be appropriate for the Mall. Jim was aware that they would be dealing with unfavorable exchange rates between England and the United States. In discussion with Wells Fargo Bank, Jim was able to gain access to a CEO Portal that allows him to buy foreign currency directly and use it to pay for purchases in other nations. This would allow him to hedge the exchange rate to provide savings that may occur in the currencies. He also could place the appropriate currency directly into the banks of foreign suppliers. In addition, he was able to find trusted logistical agents that could shepherd the goods from England through Houston and on to the Mall site. The trip was successful with the goods arriving on site at the beginning of the Fall 2008 essentially undamaged.

Throughout 2009 and into 2010, the Mall continued to grow to the point of reaching full occupancy. Although some vendors left, there were always new ones to take their place. The customer base had grown as well. Although the organizational structure was working well, Jim and Lynn were spending more time in the business than they had originally planned. It also became obvious that the organization had outgrown the original information system which had become too labor intensive and did not provide enough specific information for the vendors about the customers. Jim realized that he had to find a more efficient system that would be effective and allow some free time from the business.

In 2010, Jim began to research software, specifically designed for antique malls, that would provide a more detailed and efficient system. Appropriate software was supplied by a Houston company and the process of switching systems began. Jim and Lynn had been involved in system changes previously, so they were aware of the human factor effect of a change of this magnitude. It was imperative that dual systems run for the shortest time possible and have the system changeover be correct the first time. Memos were provided to vendors and training provided to organizational staff. Before the end of 2010, the transition was made successfully with very minor glitches.

During 2010 and 2011, the economy in Texas took a downturn and Jim realized that it may last for an extended period of time. The new information system was used to identify inefficiencies that could help cut costs. Inefficiencies were individually addressed with the idea of adjusting, eliminating, or outsourcing them. It became imperative to reduce costs while maintaining the image of an upscale operation and continuing to provide a positive customer interface. The number of staff members employed was slightly reduced and the information system efficiency was increased. For the most part, the vendors and staff understood the necessity for these actions and were supportive.

In 2011 and into 2012, the economic situation began to improve. The economic situation had eliminated a number of other antique operators in the market, which decreased the local competition. After Thanksgiving and during the Christmas and New Year holidays, Jim and Lynn discussed the next move for The Village Antique Mall which celebrated its $5^{\text {th }}$ year anniversary in April 2012. The original intention was to exit the business and cap sale the building at the end of five years. They needed to make a decision on how to proceed into the future as they went into 2013.

The Village Antique Mall had grown to be one of the largest outlets in the state of Texas with the only known larger one in Dallas. One option was to expand the organizational concept into other geographical locations. The Mall was on Facebook and getting many positive responses from places across the U.S. and abroad, so could the Mall be expanded through use of the Internet? Should Jim and Lynn sale or liquidate the business and cap sale the building? The Mall had a good organizational team and a good group of vendors. 
Jim and Lynn sat in front of the fire in the den and discussed possible options. What to do was not a simple decision, but after much reflection, the decision was made to sell the business and building as an operating entity. Jim and Lynn had been able to upgrade the building during the remodel, which included new air-conditioning units for the massive facility. The owners were able to realize a return of approximately $8 \%$ on the investment and expenses associated with upgrades to the building and business. They had learned a lot from the experience, but Jim and Lynn felt it was time to take profits and allow a new entrepreneur to tackle the world of antiques.

\section{AUTHOR INFORMATION}

Dr. John Cooley is professor of management at West Texas A\&M University in Canyon, Texas. Dr. Cooley earned a doctorate degree in management from Oklahoma State University. E-mail: jcooley@wtamu.edu

Dr. James Owens is a Hodges Professor of Corporate Governance and Finance at West Texas A\&M University in Canyon, Texas. Dr. Owens earned a doctorate degree in finance from Harvard University. E-mail: jowens@wtamu.edu

Dr. Neil Terry is dean and professor of economics at West Texas A\&M University in Canyon, Texas. Dr. Terry earned a doctorate degree in economics from Texas Tech University. E-mail: nterry@wtamu.edu (Corresponding author)

\section{REFERENCES}

1. Notte, J. (2011). Nine completely worthless collectibles. Yahoo Finance. Retrieved September 10, 2013 from http://finance.yahoo.com/news/pf_article_113722.html

2. Internet Business Statistics (2013). The growth of online shopping. Retrieved September 12, 2013 from http://www.wwwmetrics.com/shopping.htm 


\section{NOTES}

